\title{
JUSTIÇA RESTAURATIVA: UM CAMINHO PARA O ENFRENTAMENTO E A PREVENÇÃO DA VIOLÊNCIA DOMÉSTICA/FAMILIAR CONTRA A MULHER NO ESTADO DO PARÁ
}

\section{RESTORATIVE JUSTICE: A WAY TO ADRESS AND PREVENT DOMESTIC/FAMILY VIOLENCE AGAINST WOMEN IN STATE OF PARÁ}

\author{
Josineide Gadelha Pamplona Medeiros ${ }^{1}$ \\ Nirson Medeiros da Silva Neto ${ }^{2}$
}

\begin{abstract}
Resumo: $O$ artigo apresenta a justiça restaurativa como uma estratégia, entre outras possíveis e necessárias, para o enfrentamento e a prevenção da violência contra a mulher no espaço doméstico/familiar, atentando para os aspectos socioculturais relacionados a esta modalidade de violência. A partir de uma breve delimitação teórica da noção de justiça restaurativa e passando por um relato de experiências que iniciaram no cenário de Justiça Juvenil e alcançaram posteriormente o trabalho com a violência doméstica/familiar, em um estado da região Norte do Brasil, são desenvolvidas reflexões acerca dos limites e possibilidades de utilização de práticas restaurativas com vistas a promover reparação para as vítimas, responsabilização ativa dos ofensores e participação, quando adequado, de outros atores interessados (famílias e comunidade), contribuindo assim para a transformação de padrões estruturais e culturais associados a relações de gênero.
\end{abstract}

Palavras-chave: justiça restaurativa, violência de doméstica/familiar, gênero.

\begin{abstract}
The article presents restorative justice as a strategy, among other possible and necessary, for coping and preventing violence against women in the domestic/family space, taking into account sociocultural aspects related to this type of violence. From a brief theoretical delimitation of the notion of restorative justice and passing through a reporting experiences that began in the scene of Juvenile Justice and later reached the work with domestic/family violence, in one state of Brazilian North region, reflections are developed on the limits and possibilities of using restorative practices to promote reparation for victims, to be offenders accountable, and encourage participation, when appropriate, of other
\end{abstract}

\footnotetext{
${ }^{1}$ Juíza de Direito do Tribunal de Justiça do Estado do Pará. Mestre em Direito, com ênfase em Direitos Humanos, pela Universidade Federal do Pará (UFPA). Doutoranda pelo Programa de Pós-graduação em Sociedade, Natureza e Desenvolvimento da Universidade Federal do Oeste do Pará (UFOPA). Membro do Comitê Gestor da Justiça Restaurativa do Conselho Nacional de Justiça (CNJ).

${ }^{2}$ Professor Adjunto da UFOPA. Possui pós-doutorado pelo Departamento de Psicologia Social e do Trabalho, Instituto de Psicologia, da Universidade de São Paulo (USP), doutorado em Ciências Sociais, área de Antropologia, e mestrado em Direito, com ênfase em Direitos Humanos, pela UFPA. Atualmente, é membro do Programa de Pós-graduação em Ciências da Sociedade (PPGCS), coordenador da Clínica de Justiça Restaurativa da Amazônia (CJUÁ) e vice-diretor do Instituto de Ciências da Sociedade (ICS) da UFOPA.
} 
stakeholders (families and community), thus contributing to the transformation of structural and cultural patterns related to gender relations.

Keywords: restorative justice, domestic/family violence, gender.

\section{Introdução}

Nas linhas abaixo apresentamos a justiça restaurativa como uma estratégia, entre outras possíveis e necessárias, para o enfrentamento e a prevenção da violência no espaço doméstico/familiar, particularmente a perpetrada contra mulheres. Esta modalidade de violência, em suas raízes histórico-culturais, traz consigo forte relação com práticas e representações de gênero, profundamente enraizadas nas estruturas socioculturais da sociedade brasileira. No Brasil, conforme acentua Roberto DaMatta (1997), costumamos operar uma separação entre os espaços da "casa" e da "rua", representando o espaço doméstico/familiar como um lugar onde existe maior controle das relações sociais, ambiente de afeto, intimidade, calma, harmonia e descanso, sendo também o local das preocupações com a família, regido e formado pelo parentesco, bem como de uma normalizada e por isso muito comum dominação masculina e dos mais velhos. Este espaço, de acordo com o esquema interpretativo tradicional, faz oposição à "rua" que, ao contrário, é o universo do castigo, do perigo, da luta e do trabalho, assim como das coisas públicas, da atividade política e dos assuntos econômicos, no qual vislumbramos alguma incerteza nas relações, hierarquias não pautadas no parentesco ou na idade e, por fim, aproximações não "naturais" entre as pessoas, mas sim caracterizadas por certa seletividade. Normalmente, no modo como interpretamos nossa realidade social, esta dicotomia é acompanhada de uma divisão do mundo que leva em conta questões de gênero, embora nem sempre conscientes e reconhecidas, atribuindo-se um pertencimento supostamente "natural" das mulheres ao espaço doméstico/familiar e dos homens ao espaço da "rua". Este esquema interpretativo tem sido cada vez mais desafiado pelas transformações históricas da sociedade brasileira, mas ainda assim mantém-se como parte do modo como os brasileiros percebem e experimentam suas relações no mundo social.

Tal representação, evidentemente, quando cotejada com a práxis, apresenta traços que carecem de reflexão crítica, dado que traz subjacentes estruturas complexas de desapreço à e exclusão da posição feminina dentro de uma sociedade herdeira dehabitus 
patriarcais $^{3}$, dispondo as mulheres em uma posição desigual e não equitativa de interação com os homens e atuação na esfera pública. Ademais, a divisão do mundo entre a "casa" e a "rua" deixa em estado oculto a violência simbólica (ou cultural), que com certa frequência se converte em física, que dispõe as mulheres em degraus inferiores na estrutura social. A dominação masculina aparece então naturalizada, como se fizesse parte da "ordem das coisas", o que reproduz logicamente uma percepção androcêntrica da realidade. Como ensina Pierre Bourdieu (1999, p. 18), esta visão androcêntrica, porque naturalizada, "impõe-se como neutra e não tem necessidade de se enunciar em discursos que visem a legitimá-la”. A cosmovisão androcêntrica que orienta nossa percepção da vida social, além de comumente objetificar a figura feminina (a exemplo de como costumamos lidar com o corpo da mulher), não raramente é o substrato simbólico justificador da prática de agressões físicas, psicológicas, morais e sexuais, incluindo aqui as corriqueiras situações de assédio e abuso sexuais. Tratar de violência no espaço doméstico/familiar contra a mulher, portanto, significa considerar aquilo que Johan Galtung (1969; 1990) chamara de violência estrutural e de violência cultural, formas indiretas de violência que geram a ambiência social legitimadora e justificadora de violências diretas - no caso, aquelas que são praticadas em face de mulheres no espaço da "casa" e mesmo na "rua".

Como lidar com situações de violência tão complexas como a chamada violência doméstica ou familiar que, sabidamente, apresenta notável enraizamento em formas mais sutis e difusas de violência, isto é, em componentes estruturais e culturais da sociedade brasileira? Sem dúvida, estes são conflitos que apresentam aspectos subjetivos e intersubjetivos que não podem ser ignorados. Porém, uma compreensão mais integral da problemática, sem a qual torna-se improvável a transformação dos padrões subjacentes que contribuem para a ocorrência regular destas situações conflitivas, deve incluir a consideração de fatores relacionados à estrutura social e à cultura da sociedade em que se deseja realizar alguma intervenção com propósitos transformativos e preventivos de

\footnotetext{
${ }^{3}$ Segundo Pierre Bourdieu (2007, p. 86), habitus corresponde a "sistemas de disposiciones duraderas y transferibles, estructuras estructuradas predispuestas a funcionar como estructuras estructurantes, es decir, como principios generadores y organizadores de prácticas y de representaciones que pueden ser objetivamente adaptadas a su meta sin suponer el propósito consciente de ciertos fines ni el dominio expreso de las operaciones necesarias para alcanzarlos, objetivamente "reguladas" y "regulares" sin ser para nada o producto de la obediencia determinadas reglas y, por todo ello, colectivamente orquestradas sin ser el producto de la acción organizadora de un director de orquestra".
} 
outros incidentes. Por óbvio que a completa eliminação de padrões de violência histórica e culturalmente enraizados é um ideal utópico e não esperável a curto e médio prazos. Mas, para que se promova a redução nas taxas de ocorrências e a prevenção de novas ofensas, é importante o planejamento e o desenvolvimento de um conjunto sistêmico de ações capaz de enfrentar a problemática em sua natureza multifacetária e multicausal, lidando com as diferentes camadas ou dimensões dos conflitos, a saber, incluindo aspectos subjetivos, relacionais, históricos, estruturais e culturais (LEDERACH, 1997 e 2012; SCHIRCH, 2004). Como parte deste conjunto de intervenções estratégicas capaz de realizar transformações duráveis e de longo prazo nos padrões que levam à reprodução de atos de violência, Lisa Schirch (2004) sugere três pilares de ações: a transformação de conflitos, o tratamento de traumas (trauma healing) e a justiça restaurativa. Em se tratando de violência doméstica/familiar no Brasil, parece-nos claro que um conjunto de outras intervenções também poderiam e deveriam ser desenvolvidas para que possamos vivenciar mudanças do tipo long-term dos padrões sociais relacionados à violência contra a mulher. Neste artigo, dada nossa proximidade com a temática da justiça restaurativa, enfocaremos as possibilidades de uso de estratégias restaurativas para o enfrentamento e prevenção de situações de violência contra a mulher no espaço doméstico/familiar, sem que com isso estejamos ignorando a necessidade de outras intervenções que perfaçam caminhos diferentes para um enfrentamento mais sistêmico da problemática.

Nosso enfoque estará baseado nas possibilidades que a justiça restaurativa apresenta para a realização de intervenções voltadas à redução da vulnerabilidade e à prevenção de incidentes de violência no espaço doméstico/familiar, notadamente as ofensas contra mulheres relacionadas a fatores de gênero. Por se tratar de um tema complexo, controvertido - a respeito do qual muita discussão se há gerado no âmbito nacional e internacional - e só mui recentemente no Brasil, recorreremos a um relato de experiências que iniciaram em um cenário de Justiça Juvenil e alcançaram a posteriori o trabalho com a violência doméstica e familiar contra a mulher, numa cidade média do estado do Pará, o município de Santarém, onde atuamos desde 2011 na construção de um programa interinstitucional intitulado Programa de Justiça Restaurativa Amazônia da Paz. O relato focalizará, mais detidamente, os aprendizados que vimos acumulando sobre o quanto a justiça restaurativa (e suas respectivas metodologias) pode ser uma estra- 
tégia orientada ao atendimento dos reais interesses e necessidades da mulher vítima de violência doméstica/familiar, promovendo-se a responsabilização ativa do ofensor e a transformação dos padrões socioculturais que legitimam e justificam a dominação masculina, sustentada por uma visão androcêntria da realidade que normaliza a violência de gênero. Estes aprendizados, muito embora iniciados em outro campo de atuação judicial, têm mais recentemente lançado luzes e perspectivas sobre como trabalhar em segmentos do sistema de justiça e serviços correlacionados voltados mais especificamente para os assuntos da violência contra a mulher no espaço doméstico/familiar, utilizandose abordagens restaurativas para lidar com esta modalidade particularmente complexa de violência.

\section{Breve anotação sobre o conceito de justiça restaurativa}

A justiça restaurativa é uma filosofia, uma bússola teórica ou, como preferimos dizer, uma forma de imaginar e praticar a justiça que inclui, na medida do possível, vítima, agressor, famílias e comunidades no processo de construção de respostas ativas a atos que violaram pessoas e relacionamentos, gerando obrigações de reparação e atendimento de necessidades humanas (por vezes, direitos humanos básicos) que podem ser encaminhadas de modo a se evitar a reincidência de atos danosos, enfrentando-se os fatores subjacentes ao conflito - put things right, como costuma dizer o professor Howard Zehr (2008; 2015). Contudo, numa acepção restaurativa, putting right significa, entre outras coisas, promover-se a responsabilização do agressor (accountability), obter-se reparação para a vítima (ainda que muitas vezes mormente simbólica), bem como favorecer-se a participação de famílias e comunidades no tratamento do conflito com fito à construção de encaminhamentos e à prevenção de novos incidentes lesivos. Desta forma, a justiça restaurativa, em sentido estrito, implica o uso de metodologias colaborativas e inclusivas que trazem para o processo todas as pessoas interessadas e/ou que podem contribuir para o desenvolvimento de soluções e planos de ação, partiIhando responsabilidades e assumindo obrigações que visem satisfazer as necessidades de todos os envolvidos na situação conflitiva. Mas, para além disto, a experiência também nos mostra que a justiça restaurativa possui um grande potencial para estimular a estruturação de redes, a conexão entre pessoas e instituições, incentivando assim o 
trabalho interdisciplinar e multinstitucional. Assim, um resultado secundário, mas não menos importante, das abordagens restaurativas é sua contribuição para a articulação do sistema de justiça com outros serviços, instituições e grupos que atuam em diversos setores sociais, como escolas, universidades, prisões, polícias, serviços de assistência social, atendimento a adolescentes em conflito com a lei, assistência a vítimas de violência doméstica/familiar e sexual, apoio a vítimas de violência de gênero (população LGBT, por exemplo), comunidades e grupos religiosos, envolvendo profissionais de diferentes áreas do conhecimento e, não em menor grau, membros de comunidades.

Em termos históricos e antropológicos, a concepção de justiça que contemporaneamente chamamos de justiça restaurativa é correntemente associada a sistemas de justiça de base comunitária ou, para usar uma categoria cunhada por Clifford Geertz (1997), a sensibilidades jurídicas locais que caracterizam alguns povos tradicionais (os Navajo, os Maori, entre tantos outros), assim como a ideias de justiça de comunidades confessionais cristãs, com especial destaque para as menonitas. Contudo, encontramos experiências práticas e ideias de justiça homólogas em cenários comunitários e institucionais de outras partes do mundo, caracterizados pela adoção de processos colaborativos e inclusivos de tratamento de conflitos, voltados para a construção da paz, a reconciliação e a responsabilização. Porém, tal como a compreendemos hoje, a noção de justiça restaurativa emergiu a partir da década de 1970 como uma resposta à insatisfação com o sistema de justiça moderno-ocidental que tradicionalmente não considera a participação das pessoas e grupos diretamente interessados na solução de situações conflitivas em razão da centralização da responsabilidade pela resolução das contendas na figura do Estado, bem como no papel dos especialistas do campo do direito, a saber, advogados, defensores públicos, promotores, juízes e demais profissionais do mundo jurídico. Ademais, o sistema de justiça moderno, sob uma rígida estrutura moral que caracteriza as culturas ocidentais, correntemente focaliza a culpabilização individual dos ofensores/autores de ofensas e a concorrência entre os atores envolvidos, deixando de lado as necessidades reais das vítimas/receptores das ofensas, das famílias e das comunidades afetadas pelo conflito e/ou nas quais este tem ocorrido, muitas vezes de forma duradoura e não raro até mesmo intergeracional, com consequências, traumas e sequelas para um número ampliado de atores sociais (ZEHR, AMSTUTZ, MACRAE \& 
PRANIS, 2015; GIDDENS \& SUTTON, 2016).

Em resposta a esta verdadeira desapropriação dos conflitos experimentada pelos sujeitos individuais e coletivos mais diretamente afetados, princípios e práticas de justiça restaurativa passaram a ser disseminados em muitos países, inicialmente no contexto da justiça criminal, mas posteriormente vindo a ser usados, em diversas partes do mundo, em diferentes cenários onde são correntes situações conflitivas e a perpetração de atos geradores de danos a pessoas e relacionamentos. Concepções de justiça restaurativa foram (e são) encontradas em contextos conflitivos tanto de baixa como de alta complexidade, a exemplo das experiências de justiça de transição, em conjunturas de pós-guerra, pós-apartheid, qual é o caso da Comissão da Verdade e Reconciliação na África do Sul, dos Fambul Toks em Serra Leoa e das Escolas de Perdão e Reconciliação (ESPERE) na Colômbia. Embora não deva ser considerada uma panaceia aplicável a todo e qualquer tipo de conflitualidade social, a amplitude de sua aplicação demonstra a versatilidade e a adaptabilidade da bússola restaurativa a variados contextos e propósitos que envolvem questões de conflito, sendo de grande pertinência refletirmos, a partir de experiências vivenciadas, sobre os limites e possibilidades de sua utilização em situações relacionadas à violência doméstica/familiar contra mulheres, ainda que com o cuidado de considerar as particularidades deste tipo de violência, com significativo enraizamento em estruturais socioculturais de longa duração e, por isso, de difícil transformação, como visto anteriormente. No Brasil, a administração de situações de conflito fundada em ideais de justiça restaurativa passou a ser adotada há cerca duas décadas, tendo, no entanto, o Poder Judiciário como principal protagonista e centro irradiador, o que não deixa de ser uma característica do modo como incorporamos a nosso sistema social e jurídico um modelo a priori exógeno de justiça, pautado em padrões até então desconhecidos na sociedade brasileira. Este fato levou recentemente à constituição de uma política judiciária nacional, instituída pelo Conselho Nacional de Justiça (CNJ), através da Resolução 225/2016. Segundo a Resolução, justiça restaurativa:

[...] constitui-se como um conjunto ordenado e sistêmico de princípios, métodos, técnicas e atividades próprias, que visa à conscientização sobre os fatores relacionais, institucionais e sociais motivadores de conflitos e violência, e por meio do qual os conflitos que geram dano, concreto ou abstrato, são solucionados de modo estruturado na seguinte forma: I - é necessária a participação do ofensor, e, quando houver, da vítima, 
bem como, das suas famílias e dos demais envolvidos no fato danoso, com a presença dos representantes da comunidade direta ou indiretamente atingida pelo fato e de um ou mais facilitadores restaurativos; II - as práticas restaurativas serão coordenadas por facilitadores capacitados em técnicas autocompositivas e consensuais de solução de conflitos próprias da Justiça Restaurativa, podendo ser servidor do tribunal, agente público, voluntário ou indicado por entidades; III - as práticas restaurativas terão como foco a satisfação das necessidades de todos os envolvidos, a responsabilização ativa daqueles que contribuíram direta ou indiretamente para a ocorrência do fato danoso e o empoderamento da comunidade, destacando a necessidade da reparação do dano e da recomposição do tecido social rompido pelo conflito e as suas implicações para o futuro.

Trata-se, portanto, de uma concepção de justiça fincada em princípios e práticas que buscam a participação de todos os envolvidos direta e indiretamente numa situação conflitiva, bem como o atendimento das necessidades que emergem e das obrigações resultantes dos eventuais danos causados, que exigem, portanto, reparação e compartiIhamento de responsabilidades, ao invés da simples retribuição do mal e culpabilização individual administradas de forma monopolista pelo Estado e por especialistas em resolução de conflitos, com fulcro numa linguagem técnico-jurídica quase inacessível aos reais "proprietários" dos conflitos, como diria Nils Christie (1977), e que trazem, normalmente, um forte caráter moralizante, olvidando outras camadas ou dimensões de responsabilidade, partilhadas pelos demais atores interessados, incluindo a família, a comunidade e mesmo a sociedade mais amplamente considerada. Deste modo, a justiça restaurativa oferece condições que favorecem a vivência de processos participativos e dialogados de tomada de decisão, contribuindo para a construção de soluções e encaminhamentos de conflitos que envolvem comportamentos lesivos, tais como aqueles que representamos em nossa sociedade como crimes - ou atos infracionais - aqui inclusos os que resultam em violências severas (ZEHR, 2008 e 2015). Uma concepção restaurativa de justiça considera então a necessidade de tratamento não apenas dos atos danosos em si, senão igualmente as consequências, traumas e sequelas decorrentes destes atos, geralmente não tomados em conta na nossa tradição moderna-ocidental de justiça, o que, em se tratando de casos de violência doméstica/familiar contra a mulher, só são adequadamente tratados à medida que restam considerados fatores que transcendem os limites do relacionamento entre ofensor e vítima, edificando-se estratégias capazes de enfrentar os elementos socioculturais subjacentes aos atos lesivos perpetrados, via de regra, por 
homens contra mulheres no espaço da vida familiar e das relações domésticas.

\section{Justiça restaurativa: um caminho para o enfrentamento e prevenção da violência doméstica/familiar contra a mulher}

O início de nossa experiência com justiça restaurativa data dos idos de 2008, quando principiamos uma investigação sobre a política brasileira de alternativas penais e sua implementação no estado do Pará, unidade da Federação onde atuamos enquanto magistrada vinculada ao Poder Judiciário estadual e professor em uma universidade federal. Naquela época, tínhamos apenas uma experiência teórica com a justiça restaurativa, embora já houvesse no Brasil experiências significativas em curso noutras unidades da Federação. No entanto, a pesquisa sobre alternativas penais foi o evento catalisador que nos levou ao desenvolvimento de um programa de justiça restaurativa numa mesorregião da Amazônia Oriental conhecida como Baixo Amazonas. A mudança de uma experiência teórica com justiça restaurativa para uma experiência prática só ocorreu, no entanto, quando passamos a trabalhar com a Justiça Juvenil em uma comarca que concentra a execução de medidas socioeducativas em meio fechado de toda aquela mesorregião. O trabalho com a Justiça Juvenil, numa perspectiva restaurativa, tem focalizado a implantação, implementação e sustentabilidade de práticas restaurativas nos serviços relacionados ao tratamento e prevenção da delinquência juvenil, bem como à proteção de crianças e adolescentes em situação de risco social. Em parceria com diferentes organismos locais, vem sendo realizados diversos treinamentos de facilitadores, incentivando-se o desenvolvimento de redes interdisciplinares e multinstitucionais de atores com vistas à construção de abordagens restaurativas em campos variados, contando para tanto com o apoio do Instituto Terre des hommes no Brasil (Tdh), que ofereceu os primeiros cursos de formação de facilitadores e até hoje realiza treinamentos para multiplicadores/instrutores, garantindo assim a sustentabilidade das ações relacionadas à justiça restaurativa. Devido a essa coalizão de pessoas e instituições, práticas restaurativas têm sido realizadas difusamente em variados cenários. O trabalho com metodologias de justiça restaurativa tem revelado como podemos humanizar o tratamento dispensado a crianças, adolescentes, suas famílias e comunidades, utilizando-se abordagens restaurativas como os peacemaking circles (PRANIS, STUART \& WEDGE, 2003; PRANIS, 
2010) para lidar com situações de vulnerabilidade e risco social, o que, a nosso ver, enriquecera significativamente o trabalho na seara da Justiça Juvenil na região em que atuamos.

A principal pergunta que nos fazemos no presente artigo diz respeito aos limites e possibilidades de transposição de experiências como a descrita acima para o âmbito do enfrentamento e prevenção da violência doméstica e familiar contra a mulher no contexto sociocultural da sociedade brasileira, dado que o campo da Justiça Juvenil se tem demonstrado, no Brasil e em muitos outros países, um universo fértil para a utilização de abordagens restaurativas em razão das particularidades deste subsistema de justiça que considera a condição especial de crianças e adolescentes enquanto pessoas em desenvolvimento, assim como sua suscetibilidade a fatores de risco e vulnerabilidade social, devendo-se nesta seara se trabalhar no sentido da ampliação dos fatores de proteção que contribuem para um desenvolvimento saudável e seguro no ambiente social. A bem da verdade, atualmente, cremos que é correto dizer que a justiça restaurativa vem se convertendo em um standard internacional no campo da Justiça Juvenil, embora existam diferenças metodológicas e nos modos como a filosofia restaurativa é incorporada em cada subsistema jurídico particular, quer dizer, no ordenamento jurídico juvenil de cada país aderente ao modelo restaurativo. Este fenômeno, por exemplo, evidenciou-se no World Congress on Justice for Children, realizado em 2018 na casa da UNESCO, Paris - França, onde observamos o relato de autoridades políticas e judiciárias de diversos países, de culturas e continentes distintos, quanto à incorporação de sistemas restaurativos em seus respectivos ordenamentos jurídicos. Que a justiça restaurativa deva ser uma característica do subsistema da Justiça Juvenil, isto parece tornar-se cada vez mais um consenso na comunidade internacional que lida com os direitos de crianças e adolescentes. Mas quanto ao campo da violência doméstica/familiar contra a mulher, esta ainda é uma esfera que suscita e demanda discussões. É seguro se promover encontros entre vítimas e ofensores em face de conflitos relacionados a situações de convivência duradoura entre pessoas que, muitas vezes, vivenciam padrões de violência reiterada no espaço doméstico/familiar? A justiça restaurativa pode ajudar no processo de transformação de estruturas socioculturais que justificam e, de certa forma, legitimam a violência de gênero no âmbito do espaço doméstico e familiar? Em que medida as metodologias 
restaurativas são adequadas para enfrentar e prevenir este tipo particularmente complexo de violência? Os caracteres da justiça restaurativa que favorecem o trabalho em rede e a atuação interdisciplinar seriam transponíveis para a realidade do atendimento de vítimas, ofensores, famílias e comunidades envolvidos em situações de violência doméstica/familiar contra a mulher, tal como tem ocorrido no cenário da Justiça Juvenil?

A aplicação da justiça restaurativa ao contexto da violência de gênero no espaço doméstica/familiar ainda é recente no Brasil, mas o compartilhamento de algumas experiências pode ajudar a estabelecermos uma reflexão sobre as condições desta aplicação, identificando inclusive limites e possibilidades. Vamos partir de uma zona de transição entre a Justiça Juvenil e o campo da violência doméstica/familiar contra a mulher: a violência sexual contra crianças e adolescentes, que afeta tanto meninas quanto meninos, mas em maior grau as primeiras em razão de nossos padrões socioculturais. Os profissionais que trabalham com o processamento de casos de violência sexual contra crianças e adolescentes sabem que se trata de situações que, o mais correntemente, acontecem no espaço da "casa", portanto no seio da família e do grupo doméstico, perpetrada normalmente por homens que possuem vínculos de parentesco com as vítimas (como pais, avós, tios, irmãos, primos e padrastos), bem como por indivíduos com vínculos estreitos mas de outra natureza (como vizinhos, amigos e pessoas de confiança da família). Logo, envolvem sujeitos com relações duráveis, estabelecidas previamente à ofensa e que na maioria das vezes perduram após a ocorrência do ato danoso. Estes traços diferenciadores da violência sexual contra crianças e adolescentes contribuem sobremaneira para que tais ofensas permaneçam em estado latente, não declaradas e ocultas, não raramente sendo negadas pelas próprias vítimas, posto que seu desvelamento pode trazer sérias consequências a pessoas com quem possuem relações préestabelecidas, embora muitas vezes marcadas por certa ambiguidade, já que a um só tempo se caracterizam por padrões de violência e afetividade, desconfiança e lealdade, sendo atravessadas por necessidade de pertencimento e de libertação, o ofensor representando tanto risco quanto proteção para a pessoa vitimizada. Este aspecto relacional ambíguo costuma provocar muita confusão na percepção da vítima e nas emoções associadas à situação de abuso/assédio vivenciada, bem como no tangente à relação com o agressor, ademais do fato em si de se tratar de crianças e adolescentes em processo de 
descoberta e desenvolvimento da sexualidade, com uma compreensão ainda não completamente formada a respeito das funções sexuais em sua vida e de como podem ser experienciadas de forma saudável.

Um caso que pode ser ilustrativo do que estamos falando foi encaminhado à Vara da Infância e Juventude em que atuamos, sendo abordado através de uma prática restaurativa, somada a um conjunto de outras intervenções desenvolvidas de forma interdisciplinar e multinstitucional. Tratava-se de uma adolescente que sofrera reiterados atos de abuso sexual praticados por seu padrasto - aliás, situação recorrente em municípios da região Norte do Brasil. Quando a mãe descobrira que a jovem estava sendo vítima de abusos por parte de seu próprio marido, no espaço da "casa" - outrora lugar de aconchego, segurança, descanso, calma e afetividade, representação que então fora completamente rompida pela descoberta dos atos delitivos continuados - saíra com a filha do município em que residiam, no estado do Maranhão, enveredando em uma difícil jornada até fixarem-se na cidade de Santarém, estado do Pará. Para além dos aspectos criminais do caso, que seguiram os caminhos tradicionais da justiça penal, as ofensas trouxeram consequências, traumas e sequelas que extrapolaram a relação da vítima com o ofensor, deixando não apenas prejuízos à adolescente no que concerne à violação de seu corpo, de sua estabilidade psicoemocional, de sua sexualidade, etc., mas também ao relacionamento entre mãe e filha, doravante fissurado porque atravessado por desconfiança e confusas representações de deslealdade. De certo modo, embora a genitora tenha apresentado uma atitude protetiva ao retirar a filha da convivência com o abusador, após a descoberta do ato delitivo passou a externalizar desconfiança em relação à vítima, que restou por ela culpabilizada por sua própria vitimização, como se tivesse, em alguma medida, "deslealmente" contribuído para a ofensa. Em outras palavra, a mãe sentia-se traída pela filha que fora abusada sexualmente por seu cônjuge. Este caso revela aquilo que falamos na introdução acerca dos habitus patriarcais da sociedade brasileira, isto é, disposições interiorizadas que nos levam a não perceber os arbitrários que se ocultam por detrás de fatos como a culpabilização da mulher que sofrera violência sexual. Tais habitus se manifestam em pensamentos, ações, percepções e formas de apreciação subjetivas ainda quando completamente ignorados (BOURDIEU, 2007; 2008), como acontecera com a mãe da adolescente no caso relatado, ao atribuir culpa a sua filha 
por uma violência sexual por esta sofrida sem perceber o arbitrário cultural (ou violência simbólica) oculto por detrás desta representação. Mas como lidar com referida situação de conflito entre mãe e filha? Seria da competência do sistema de justiça lidar com esta situação, ou o caso deveria ser deixado a psicoterapeutas de família e aos profissionais do atendimento psicossocial?

Independentemente da necessária intervenção psicoterapêutica e psicossocial, o caso foi encaminhado ao sistema de justiça em razão de apresentar, dada sua complexidade e diversidade de fatores de risco, situação de vulnerabilidade para a adolescente, vítima de abuso sexual do padrasto, estando no momento distante de seu lugar de residência, de sua família e comunidade de apoio, em conflito com a mãe/esposa do abusador que desenvolvera sentimento de que a filha fora desleal para com ela ao copular com seu marido - ainda que esta possa nos parecer uma percepção absurda, na realidade, paradoxalmente, é uma reação bastante comum em casos semelhantes. Após judicializado, o caso foi direcionado para a aplicação de medidas protetivas e, entre elas, recomendou-se a realização de uma prática restaurativa entre mãe e filha, com vistas a se tratar o conflito por elas vivenciado e se construir, conjuntamente com a equipe interdisciplinar do Centro de Referência Especializado em Assistência Social (CREAS) e um facilitador da universidade, estratégias e planos de ação para enfrentar os múltiplos aspectos que contribuíam para a vulnerabilidade da adolescente e a situação de risco por que estava passando. Deste círculo restaurativo, dois significativos resultados que nos recordamos, entre outros encaminhamentos, foram: (1) para todos os participantes, uma compreensão mais ampliada da problemática, associada a questões de gênero e a estruturas socioculturais que favorecem interpretações androcêntricas dos fenômenos vivenciados na experiência social, inclusive as situações de violência sexual; e principalmente (2) o fortalecimento dos vínculos entre mãe e filha, ambas afetadas - ainda que em graus diferentes - por atos ofensivos de um homem que trouxeram profundos efeitos para suas vidas, incluindo violações físicas e psicoemocionais, rupturas relacionais, mudança abrupta de residência, rompimento da convivência com a comunidade de apoio e com o grupo doméstico/familiar, perda de segurança e de sentido da vida, precarização socioeconômica, intervenção de agentes estatais em suas vidas, participação em rituais do sistema de justiça (inquérito policial, processo judicial, inquirições, audiências, perí- 
cias, etc.), entre outras consequências cuja lista podemos dispensar, mas que integram o conjunto dos efeitos, traumas e sequelas gerados pelo delito e experimentados tanto pela filha quanto pela mãe.

Ainda no que tange à violência sexual contra crianças e adolescentes no espaço doméstico/familiar, cremos interessante trazer outro exemplo ilustrativo. Durante um curso de formação de facilitadores, ouvimos o depoimento de como os círculos vem sendo utilizados por um organismo comunitário confessional que integra a rede de proteção infanto-juvenil no município em que atuamos, a Pastoral do Menor, com vistas a identificar situações de violência sexual de que são vítimas crianças e adolescentes atendidas por referida organização socioassistencial. De acordo com o relato, um dos desafios do trabalho da Pastoral com este tipo de violação de pessoas e relacionamentos corresponde exatamente ao fato de serem situações a respeito das quais as vítimas normalmente possuem dificuldades de falar sobre a violência que vêm sofrendo no espaço doméstico/familiar, mesmo dentro de ambientes seguros como costumam ser os atendimentos psicossociais, realizados por profissionais especializados no âmbito da Pastoral. Depois da introdução da metodologia dos processos circulares no cotidiano de trabalho da organização, aumentaram significativamente o número de crianças e adolescentes que, estando em um lugar seguro, ético e transparente, sentiram-se à vontade para partilhar experiências de assédio e abuso sexuais vivenciadas no ambiente doméstico/familiar, dando assim oportunidade para que os profissionais e colaboradores da Pastoral pudessem desenvolver planos de ação, realizar intervenções e dar encaminhamentos a fim de fazer cessar as violações e prevenir novos incidentes envolvendo as crianças e adolescentes que sinalizaram estar experimentando ou já ter experimentado situações de violência sexual no espaço da "casa" ou mesmo da "rua". Ou seja, o uso dos peacemaking circles, neste contexto específico, tem sido uma importante ferramenta para o tratamento e prevenção de crimes sexuais contra crianças e adolescentes em situação de vulnerabilidade e risco social, que são os usuários dos serviços ofertados pela Pastoral do Menor. A despeito de uma metodologia originalmente voltada para processos restaurativos que, em princípio, implicam o encontro entre ofensores e vítimas, com a participação das famílias e da comunidade, nada obsta que os círculos sejam ferramentas metodológicos para se oferecer suporte às vítimas, abordando-se consequências, 
traumas e sequelas das violações com fito a se promover processos de restauração ou "cura" (o termo em inglês healing talvez seja mais feliz ao significar o restabelecimento do estado de saúde), ou mesmo para se identificar e compreender situação de violência já experimentadas ou ainda em curso.

Estes dois exemplos, ainda que coletados na esfera da Justiça Juvenil, introduzem-nos ao campo da violência doméstica/familiar contra a mulher, porque ambos estão relacionados a violações com forte caráter de gênero e atravessadas pelas estruturas socioculturais androcêntricas que, de certo modo, justificam e legitimam socialmente as correntes agressões praticadas contra pessoas do sexo feminino no espaço do grupo doméstico e da família. Nos dois casos estratégias de justiça restaurativa demonstraram-se úteis no sentido de tratar e prevenir situações de violência sexual contra mulheres, ainda que menores de 18 (dezoito) anos, no contexto da "casa". Mas até que ponto podemos transpor estas experiências ao universo mais amplo da violência doméstica/familiar sofrida por mulheres adultas, é o que gostaríamos de explorar nas páginas que nos restam. Esta demanda nos chegou, pela vez primeira, quando a partir de 2017 o CNJ, sob a regência da Ministra Cármen Lúcia, deliberou incluir a justiça restaurativa como parte da programação da 8ª Semana da Justiça pela Paz em Casa, uma das ações resultantes da Política Judiciária Nacional de Enfrentamento à Violência Contra as Mulheres no Poder Judiciário, instituída pela Portaria n. 15/2017. Doravante, emergiu a necessidade de capacitar profissionais que trabalham no campo da violência doméstica/familiar contra a mulher em metodologias e abordagens restaurativas, 0 que passamos a fazer a partir de julho daquele ano na comarca em que atuamos, ainda considerando que se tratava de um estágio de experimentação que auxiliaria no sentido de se avaliar os limites e possibilidades da aplicação de práticas restaurativas no enfretamento e prevenção desta modalidade complexa de conflito social. Nesta primeira formação e em outra que lhe sucedeu no ano seguinte, participaram membros da Vara da Violência Doméstica e Familiar contra a Mulher, assim como representantes de outros organismos que integram a rede de proteção e atendimento à mulher vítima de violência doméstica/familiar, o que já nos revelou alguns desafios da transposição de experiência com justiça restaurativa na Justiça Juvenil para um outro campo de atuação.

Deveras, a principal preocupação dos profissionais que atuavam na seara do en- 
frentamento e prevenção da violência contra a mulher no espaço doméstico/familiar consistia na promoção de encontros entre vítima e ofensor, posto que outros usos das metodologias restaurativas vinham ao encontro de práticas já realizadas por suas equipes interdisciplinares de trabalho, tais como a realização de encontros entre vítimas e encontros entre ofensores, separadamente, a fim de se oferecer suporte psicoemocional às primeiras e de se enfrentar as racionalizações dos agressores no que concerne a justificativas legitimadoras (androcêntricas) das agressões praticadas contra mulheres. Por isso, logo estes profissionais perceberam o quanto os peacemaking circles poderiam incrementar seus instrumentais metodológicos no tangente à realização de processos grupais envolvendo separadamente vítimas e ofensores, e foi-lhes um alento escutar a apresentação dos graus de justiça restaurativa, segundo o modelo de Paul McCold e Ted Wachtel (2003), que classificam as práticas em: 1) totalmente restaurativas (encontro vítima, ofensor e comunidade); 2) majoritariamente restaurativas (encontro vítima e ofensor); e 3) parcialmente restaurativa (encontros separados com vítima e/ou ofensor). Os profissionais então perceberam que, em algum grau, sua atuação já era restaurativa. Esta experiência nos demonstra que, no campo da violência doméstica/familiar contra a mulher, as estratégias e metodologias restaurativas não precisam sempre e necessariamente ser utilizadas para a promoção de diálogos entre vítimas e ofensores, com vistas à reparação e à responsabilização, com participação das famílias e da comunidade. Uma experiência do tipo putting things right pode ser vivenciada neste contexto em ocasiões voltadas exclusivamente ao apoio e suporte às vítimas que, de algum modo, contribuam para o restabelecimento do sentido da vida, da sensação de segurança, do sentimento de controle, da estabilidade financeira, etc., favorecendo processos de "cura" (healing) de traumas e sequelas causados pelo histórico de atos danosos sofridos; bem como em ocasiões que estimulem a responsabilização ativa dos ofensores, de modo que se auto-reconheçam accountable por seus atos, isto é, responsáveis de sorte a desenvolverem ações efetivamente reparadoras dos danos causados, aderindo ainda a medidas capazes de prevenir novas ocorrências semelhantes ou sob idênticas motivações (como a participação em grupo de enfrentamento ao consumo de álcool, tratamento contra dependência química, conscientização dos fatores socioculturais que subjazem à violência de gênero e assim por diante). 
O tema dos encontros entre vítimas e ofensores, no entanto, conquanto no princípio tenha se apresentado mais crítico aos profissionais do campo da violência doméstica e familiar contra a mulher, recebera sua adesão após o esclarecimento de um mal-entendido inicial, o qual se demonstrou importante para dirimir algumas estruturas prévias de compreensão em relação ao uso de práticas restaurativas neste campo específico do sistema de justiça. Referimo-nos à confusão conceitual que paira no senso comum e até mesmo entre especialistas da área no que diz respeito à mediação e à justiça restaurativa, visto que a não muito clara diferenciação entre estas duas categorias conceituais tem levado frequentemente a se considerar perigosa a promoção de encontros entre vítimas e ofensores quando estamos a lidar com agressões que se dão no âmbito doméstico e familiar. A este respeito cremos importante lembrar a lição de Zehr (2015) que acentua como um traço diferenciador das práticas restaurativas o fato de vítima e ofensor não se apresentarem no processo em papéis indiferenciados e numa condição de paridade, senão ao contrário em papéis distintos e claramente delimitados, assim como em uma condição evidentemente disparitária, haja vista que uma se apresenta na condição de vítima/receptora da ofensa e o outro no papel de ofensor/autor do ato danoso. Por via de consequência desta delimitação prévia de posições, em um processo restaurativo os participantes são estimulados a construir encaminhamentos e planos de ação que, em primeiro lugar e acima de tudo, buscam atender as necessidades da vítima, propiciando-Ihe, na medida do possível, uma experiência de reparação (ainda que muitas vezes simbólica, sobretudo quando uma reparação material não é possível ou suficiente para processar a questão). Por outro lado, a prática restaurativa deve incentivar o ofensor a apresentar respostas concretas e efetivas às consequências nefastas do ato danoso, tanto diretas quanto indiretas, de modo que se torne responsável pelos resultados de sua ação, corrigindo aquilo que pode ser corrigido, restaurando o que pode ser restaurado, mitigando os efeitos do que não é possível retornar ao estado anterior, assim como assumindo compromissos com a transformação dos fatores que motivaram o comportamento lesivo. Quando adequado, este processo pode ser experienciado com a presença de membros das famílias da vítima e do ofensor, bem como com a participação da comunidade, aqui entendida como comunidade de apoio (apoiadores indicados pelas partes) ou, a depender do caso, como comunidade afetada. 
A partir das primeiras formações para facilitadores no contexto da violência doméstica e familiar contra a mulher, temos visto ocorrer com certa regularidade encontros restaurativos, no sentido integral de termo, realizados por profissionais que trabalham no campo do enfrentamento e prevenção da violência de gênero no espaço doméstico/familiar, os quais vêm demonstrando entusiasmo com os resultados observados, particularmente diante dos casos que não chegaram a consumar agressões físicas mais graves, registrando por vezes apenas ameaças e ofensas verbais/morais. Muitos destes incidentes ofensivos que outrora não chegariam ao conhecimento do Poder Judiciário, com a expansão do direito penal a segmentos antes não abarcados pelas instituições de administração institucional de conflitos - o que incentiva uma dinâmica crescente de judicialização da vida social (SILVA-SÁNCHEZ, 2002) -, tendem a migrar da esfera privada para a esfera pública, sendo institucionalizados em decorrência de percepções do judiciário como o guardião das promessas emancipatórias e da concretização histórica dos direitos legal e constitucionalmente assegurados (GARAPON, 2001). Muito embora não descartemos a priori a possibilidade de utilização de práticas restaurativas em casos de natureza grave, no espaço de tempo que temos acompanhado o uso de abordagens restaurativas no campo da violência doméstica/familiar contra a mulher, são visíveis resultados positivos em casos de crimes de menor ofensividade, não apenas no sentido da devolução aos "proprietários" dos conflitos do poder de gerir as situações conflitivas em que estão envolvidos - só que agora em um espaço seguro, ético e transparente, fora do cenário onde se originaram e são cotidianamente vivenciadas -, como também no sentido da construção de estratégias de enfretamento e prevenção consentâneas com as necessidades das vítimas de fazer cessar as ofensas e prevenir novas ocorrências, evitando-se uma escalada do conflito que correntemente leva ao agravamento da violência contra a mulher no âmbito da "casa", a qual não raramente ocorre após a institucionalização da situação conflitiva junto à autoridade policial e sua consequente judicialização posterior.

O objetivo das práticas restaurativas no âmbito da violência doméstica/familiar contra a mulher evidentemente não é promover o perdão e a reconciliação entre vítima e ofensor - isto precisa estar bem claro, como aliás também ensina Zehr (2015) -, mesmo nos casos de crimes de menor gravidade, embora este possa ser um resultado secundá- 
rio do processo, ainda que não seja o propósito da prática restaurativa. Ao revés disso, visa-se enfrentar a situação de risco e vulnerabilidade em que se encontra a mulher, envidando-se esforços para se evitar a revitimização e a ocorrência de agravos, bem como buscando-se a responsabilização do agressor e a transformação dos fatores que motivaram a agressão, tais como a visão androcêntrica que legitima e justifica a dominação masculina e o conjunto das racionalizações que the são correspondentes, acabando por estimular atos agressivos em decorrência de fatores de gênero. Evidentemente que, em nosso contexto de atuação, os resultados até aqui observados são muito incipientes para se estabelecer uma avaliação mais aprofundada e rigorosa dos limites e possibilidades do uso de estratégias restaurativas para o enfrentamento e prevenção da violência contra a mulher no espaço doméstico/familiar. Mas sem dúvida, pelo que notamos sem a necessidade de análises mais acuradas, a perspectiva tradicional, exclusivamente retributiva e excessivamente punitivista, focada na intervenção das instituições estatais e no aprisionamento dos autores de ofensas no ambiente doméstico/familiar, pouco tem contribuído para transformações mais profundas das estruturas e padrões socioculturais que favorecem a violência contra a mulher tanto no espaço da "casa" quanto da "rua", isto é, na esfera privada como na pública. As práticas restaurativas, nesta conjuntura, emergem como uma possibilidade de se desenvolver novas estratégias de enfrentamento e prevenção que se apresentem mais conformes aos reais interesses e necessidades das vítimas que, frequentemente, não perpassam pelo encarceramento do agressor - com quem, no mais das vezes, partilham uma vida comum, não rara acompanhada de filhos, do senso de constituição de uma família e até mesmo de dependência financeira -, senão pela (re)construção de um relacionamento saudável e respeitoso que dista dos padrões de opressão anteriormente vivenciados, que favoreceram atos de violência.

\section{Considerações finais}

Chegamos ao final deste artigo com a sensação de que apenas iniciamos um processo de investigação capaz de nos levar a uma compreensão mais integral da problemática da violência doméstica/familiar contra a mulher, assim como dos limites e possibilidades da justiça restaurativa (e suas respectivas metodologias) ser uma bússola capaz de auxiliar no enfrentamento e prevenção desta modalidade tão complexa de vi- 
olência, atravessada por fatores históricos, estruturais e culturais fortemente enraizados na sociedade brasileira. Sabemos que a justiça restaurativa é apenas mais uma entre um conjunto de outras estratégias possíveis e necessárias para que se possa, sistemicamente, construir os pilares para uma transformação sustentável e de longo prazo em face de padrões historicamente marcados pela opressão das mulheres perante os homens, os quais se revelam não apenas na situação de violência doméstica e familiar, senão também em outras inúmeras circunstâncias da vida social, como a divisão sexual entre os espaços sociológicos da "casa" e da "rua", o valor dos salários e das remunerações, a ocupação dos postos de trabalho, a exposição dos corpos nas bancas de revista e na rede mundial de computadores, a representatividade nos partidos e cargos políticos, e assim por diante. Sem dúvida, jamais antes na nossa história estivemos tão conscientes e decididos a mudar estes padrões socioculturais; o endurecimento de nossa legislação penal em face dos casos de violência contra a mulher em razão de fatores de gênero é um sinal de nosso profundo desejo societário de transformação. Contudo, os verdadeiros revolucionamentos nos padrões de opressão não acontecem ao preço da inversão daqueles que ocupam os papeis de opressores e de oprimidos, senão pelo combate da própria opressão, como já nos ensinara Paulo Freire (1987). Neste sentido, o encarceramento de autores de violência doméstica/familiar se apresenta apenas como uma medida paliativa, necessária para fazer cessar uma situação opressiva insustentável, mas não representa uma mudança de padrão, portanto uma transformação do conflito.

Estratégias do tipo long-term, duradouras e com possibilidades de sustentação, precisam ser desenvolvidas se desejamos efetivamente o processamento de mudanças culturais capazes de apresentar impactos no modo como lidamos com as relações de gênero na sociedade brasileira, e isto deve perpassar por diversos aspectos de nossa vida social, entre eles os modos como administramos os conflitos que levam à violência doméstica/familiar contra a mulher. Retirar, em todo e qualquer caso de violência desta natureza, a dignidade das mulheres de vindicar um tratamento justo e indicar a maneira como gostariam de processar os atos danosos de que foram vítimas, atribuindo a responsabilidade exclusiva para tanto a especialistas que integram as estruturas burocráticolegais do Estado brasileiro, não nos parece uma forma de empoderá-las e restituir a força que Ihes foi arbitrariamente tomada pelo autor da ofensa de que foram vítimas. A 
justiça restaurativa nos parece um caminho capaz de atender melhor os reais interesses e necessidades das vítimas que procuram os organismos do sistema de justiça reportando situações de violência doméstica/familiar por elas sofridas, posto que a resposta tradicional do sistema - o aprisionamento do ofensor - em muitos casos não corresponde às expectativas das vítimas que acionam o Estado em busca de intervenções que promovam o cessar do processo de opressão. Em certos casos de violências graves, é indubitável a necessidade de intervenções que retirem o agressor da convivência social, como forma de proteger as vítimas de comportamentos potencialmente lesivos, mas mesmo nestes casos práticas restaurativas podem ser utilizadas como recursos paralelos voltados à reparação das vítimas e à responsabilização ativa dos ofensores, com ou sem a participação das famílias e da comunidade, conforme a situação factual. Em outras circunstâncias, porém, a justiça restaurativa pode ser o modelo de intervenção mais adequado para se processar violações de pessoas e relacionamentos ocorridas no espaço doméstico/familiar, dada sua filosofia reparadora e, ao mesmo tempo, de responsabilização, com abertura para processos participativos e inclusivos de outros atores que possam contribuir com encaminhamentos e na construção de planos de ação que ajudem no atendimento das necessidades de todos os envolvidos e na prevenção de ulteriores ocorrências delitivas.

\section{Referências}

BOURDIEU, P. A reprodução: elementos para uma teoria do sistema de ensino. Trad. Reynaldo Bairão. Petrópolis, RJ: Vozes, 2008. ——. El sentido práctico. Trad. Ariel DiIon. Buenos Aires: Siglo XXI, 2007. - - A dominação masculina. Trad. Maria Helena Kuhner. Rio de Janeiro: Bertrand Brasil, 1999. CHIRSTIE, N. Conflicts as property. The British Journal of Criminology, vol. 17, issue 1, pp. 1-151, jan. 1977.

DAMATTA, R. Carnavais, malandros e heróis: para uma sociologia do dilema brasileiro. 6. ed. Rio de Janeiro: Rocco, 1997.

A casa \& a rua. 5. ed. Rio de Janeiro: Rocco, 1997.

FREIRE, P. Pedagogia do oprimido. 17. ed. Rio de Janeiro: Paz e Terra, 1987.

GALTUNG, J. Violence, Peace and Peace Research. Journal of Peace Research, vol. 6, no. 3, pp. 167-191, 1969.

-. Cultural violence. Journal of Peace Research, vol. 27, no. 3, pp. 291-305, aug. 1990.

GARAPON, A. O juiz e a democracia: o guardião das promessas. 2. ed. Trad. Maria 
Luiza de Carvalho. Rio de Janeiro: Revan, 2001.

GEERTZ, C. O saber local: novos ensaios em antropologia interpretativa. Trad. Vera Mello Joscelyne. Petrópolis: Vozes, 1997.

GIDDENS, A; SUTTON, P. W. Conceitos essenciais da sociologia. Trad. Claudia Freire. São Paulo: UNESP, 2016.

LEDERACH, J. P. Transformação de conflitos. Trad. Tônia Van Acker. São Paulo: Palas Athena, 2012.

-. Building peace: sustainable reconciliation in divided societies. Washington, DC, USA: United States Institute of Peace Press, 1997.

MCCOLD, P.; WACHTEL, T. Em busca de um paradigma: uma teoria de justiça restaurativa. XIII Congresso Mundial de Criminologia. Rio de Janeiro, 10-15 de agosto de 2003. Disponível em:<https://www.iirp.edu/eforumarchive/4279-em-busca-deum-paradigma-uma-teoria-de-justica-restaurativa>.Acesso em: 15 de junho de 2018.

PRANIS, K.; STUART, B.; WEDGE, M. Peacemaking circles: from crime to community. St. Paul, Minnesota, USA: Living Justice Press, 2003.

PRANIS, K. Processos circulares de construção de paz. Trad. Tônia Van Acker. São Paulo: Palas Athena, 2010.

SCHIRCH, L. The little book of strategic peacebuilding. Intercourse, PA, USA: Good Books, 2004.

SILVA-SÁNCHEZ, J. M. A expansão do Direito Penal: aspectos da política criminal nas sociedades pós-industriais. Trad. Luiz Otavio de Oliveira Rocha. São Paulo: Revista dos Tribunais, 2002.

ZEHR, H.; AMSTUTZ, L.S.; MACRAE, A.; PRANIS, K. The big book of restorative justice. New York, USA: Good Books, 2015.

ZEHR, H. The little book of restorative justice. In: ZEHR, H.; AMSTUTZ, L.S.; MACRAE, A.; PRANIS, K. The big book of restorative justice. New York, USA: Good Books, 2015.

Trocando as lentes: um novo foco sobre o crime e a justiça. Trad. Tônia Van Acker. São Paulo: Palas Athena, 2008. 